Published in final edited form as:

Technol Innov. 2016 September ; 18(2-3): 85-98. doi:10.21300/18.2-3.2016.85.

\title{
ECONOMIC EVALUATIONS OF INTERVENTIONS FOR TRANSTIBIAL AMPUTEES: \\ A SCOPING REVIEW OF COMPARATIVE STUDIES
}

M. Jason Highsmith ${ }^{1,2,3}$, Jason T. Kahle ${ }^{4,5}$, Amanda Lewandowski ${ }^{6}$, Tyler D. Klenow ${ }^{7}$, John J. Orriola ${ }^{8}$, Rebecca M. Miro ${ }^{1}$, Owen T. Hill ${ }^{9}$, Sylvia Ursula Raschke ${ }^{10}$, Michael S. Orendurff $^{11}$, James T. Highsmith ${ }^{12,13}$, and Bryce S. Sutton ${ }^{14}$

${ }^{1}$ School of Physical Therapy \& Rehabilitation Sciences, University of South Florida, Tampa, FL, USA

${ }^{2}$ Extremity Trauma \& Amputation Center of Excellence (EACE), U.S. Department of Veterans Affairs, Tampa, FL, USA

${ }^{3} 319^{\text {th }}$ Minimal Care Detachment, U.S. Army Reserves, Pinellas Park, FL, USA

${ }^{4}$ OP Solutions, Tampa, FL, USA

${ }^{5}$ Prosthetic Design + Research, Tampa, FL, USA

${ }^{6}$ Select Physical Therapy, Brandon, FL, USA

${ }^{7}$ Prosthetics and Sensory Aids Service, James A. Haley Veterans' Hospital, Tampa, FL, USA

${ }^{8}$ Shimberg Health Sciences Library, University of South Florida, Tampa, FL, USA

${ }^{9}$ Extremity Trauma \& Amputation Center of Excellence (EACE), San Antonio Medical Center, Fort Sam Houston, TX, USA

${ }^{10}$ Center for Rehabilitation Engineering and Technology that Enables (CREATE), BCIT

Technology Centre, Burnaby, Canada

${ }^{11}$ Motion \& Sports Performance Laboratory, Lucile Packard Children's Hospital Stanford, Palo Alto, CA, USA

${ }^{12}$ Dermatology Service, James A. Haley Veterans' Hospital, Tampa, FL, USA

${ }^{13}$ Dermatology Surgery Institute, Lutz, FL, USA

${ }^{14}$ Center of Innovation on Disability and Rehabilitation Research (CINDRR-TPA), James A. Haley Veterans' Hospital, Tampa, FL, USA

\section{Abstract}

Transtibial amputation (TTA) is life-altering emotionally, functionally, and economically. The economic impact to all stakeholders is largely unknown, as is the cost-effectiveness of prosthetic intervention. This scoping report's purpose was to determine if there is sufficient evidence to

Address correspondence to M. Jason Highsmith, Extremity Trauma \& Amputation Center of Excellence (EACE), 8900 Grand Oak Circle (151R), Tampa, FL 33637-1022, USA. Tel: +1 (813) 558-3936; Fax: +1 (813) 558-3990; michael.highsmith@ va.gov. 
conduct a formal systematic review or meta-analysis in any particular prosthetic intervention area and to determine if any evidence statements could be synthesized relative to economic evaluation of interventions provided to patients with TTA. The scoping review revealed six articles representing three topical areas of transtibial care: Care Models, Prosthetic Treatment, and Prosthetic Sockets. All six articles were cost-identification or cost-consequence design and included a total of 704 subjects. Presently, it can be concluded with moderate confidence that specific weight-bearing and total-contact sockets for transtibial amputees are functionally and economically equivalent in the short term when costs, delivery time, and all stakeholder perspectives are considered. Long-term socket outcomes are relatively unexplored. Further primary research is needed beyond this to determine cost-effectiveness for other areas of transtibial prosthetic care although clinical outcomes are somewhat established through systematic review and meta-analysis in other areas of care. Conversely, evaluation of narrative economic reports relative to transtibial care may be sufficient to warrant further analysis. Guidance from the profession may also be useful in devising a strategy for how to assure economic analyses are a routine element of future prosthetic science.

\section{Keywords}

Cost-benefit; Cost-consequence; Cost-effectiveness; Cost utility; Cost identification; Health economics; Prosthetic socket

\section{INTRODUCTION}

Persons with transtibial amputation (TTA) commonly use prostheses to ambulate. Prosthetic provision is a considerable health care expense over the lifetime for TTA patients. Estimated lifetime prosthetic costs for an individual with unilateral lower limb amputation could range from $\$ 0.5$ to $\$ 1.8$ million depending on many factors, such as the number and type of prostheses in service at a given time (1). Collectively, care for the amputee of dysvascular etiology has societal costs (U.S.) of an estimated $\$ 4.3$ billion, and Medicare reimbursed $\$ 655$ million worth of lower limb prosthetic services in $2009(2,3)$.

Given the numerous intervention options and costs associated with amputee rehabilitation and prosthetic provision, it is problematic that the literature's ability to guide clinical practice, reimbursement, or health care policy is limited. For example, prominent reviews on the subjects of foot prescription (4) and post-operative management (5) indicate that no clinical recommendations can be made due to a lack of evidence. Within the prosthetic profession, this is problematic given the 2012 report by the U.S. Office of the Inspector General indicating $\approx \$ 4.7$ million worth of Medicare billings were inappropriate (2). Moreover, some insurers impose a one-limb-per-lifetime reimbursement limit, further substantiating the need for economic data related to TTA prosthetic care (6).

Another consideration is that TTA patients develop secondary conditions related to sound limb overuse, prosthetic malalignment, and other factors, including degenerative joint disease, osteopenia, postural issues, low back pain, and others (7). Each of these secondary complications has health care utilization and cost implications that are unexplored with regard to this population. Nevertheless, many TTA patients lead functional lifestyles (8), at 
times participating in sport and athletic pursuits (9). Incorporation of a prosthesis is routinely part of the rehabilitation and reintegration plan (10).

A 2013 analysis of Medicare beneficiaries (2008 Jan 1 to 2009 Jun 30) with recent lower limb amputation reported that, compared to non-prosthetic users, those who received prostheses had comparable Medicare episode payments (including prosthetic costs: $\$ 68,040$ vs. $\$ 67,312 ; p>0.05$ ) and superior outcomes (i.e., fewer emergency room admissions 1.6 vs. $2.1 ; p<0.05)(11)$. Prosthetic users were more likely to receive outpatient therapy compared with non-prosthetic users (27.2 more visits; $p<0.05)$. Physical therapy participation was associated with fewer acute care hospitalizations and less facility-based care $(p<0.05)$, which offsets the initial high cost associated with prosthetic provision. In other words, the higher initial costs decrease the burden on the health care system by decreasing utilization and adverse events. This cost savings provides insight into costs not paid (i.e., resources saved) as a result of proper rehabilitative care including prosthetic provision. This savings might be considered value. These data (11) further suggest the prosthesis was nearly amortized at 12 months, and users may experience higher quality of life and increased independence compared to non-prosthetic users.

Given the recent reimbursement challenges based on a lack of clinical and economic evidence, there is a need to understand and document the cost-effectiveness of prosthetic rehabilitation for TTA patients. Therefore, this project's purpose was to conduct a systematic scoping review of the literature to determine if clinical sub-topics had sufficient evidence for further systematic review and meta-analysis. Additionally, the review sought to formulate evidence statements related to prosthetic interventions for persons with TTA from an economic evaluation perspective based solely on comparative studies.

\section{METHODS}

On the assumption that economic evaluations for TTA prosthetic interventions would be limited, investigators opted for an inclusive search considering any element of the prosthesis (foot, ankle, pylon, socket, liner, suspension) as well as complete prosthetic care. On November 18, 2015, three databases-MEDLINE (Pubmed), The Cumulative Index to Nursing and Allied Health Literature (CINAHL) (Ovid), and the Cochrane Database of Systematic Reviews-were systematically searched for combinations of the following primary search terms:

\section{(prosthe $\mathrm{OR}^{\mathrm{O}}$ "Prostheses and Implants" OR prosthesis OR prostheses OR preprosthe ${ }^{\star}$ OR pre-prosthe $\left.{ }^{\star}\right)$}

\section{AND \\ (((transtibial OR trans-tibial OR trans tibial OR below knee OR bka OR tta OR Leg[Mesh] OR leg OR legs OR lower limb OR lower limbs OR lower extremity OR lower extremit ^ OR "Lower Extremity”[Mesh])))}

Primary search terms were combined systematically with the following secondary search terms: 


\section{Cost OR Econ` OR Efficacy OR “Cost Benefit” OR "Cost Effectiveness" OR "Cost Utility" OR "Healthcare Econ»"}

The following date limits were implemented as part of the database search parameters: 1997 Jan 1 through 2015 Nov 15.

\section{Article Screening}

Resulting references were exported to EndNote (vX6, Thompson, CA, USA) reference management software, where Stage 1 screening was applied. Stage 1 screening, including a title and abstract review and the elimination of duplicate references, was applied. Remaining economic evaluation articles were sorted by topic. Exclusion criteria were applied starting at Stage 1 to eliminate studies that merely describe costs but otherwise lack cost comparison. Foreign language articles were eliminated because of prohibitive translation fees. Economic evaluation articles from developing nations were excluded due to an inability to apply their findings to the U.S. health care market. Articles were screened for exclusion using the following criteria within EndNote:

1. Foreign language (i.e., non-English language)

2. Developing countries

3. Any study lacking an economic evaluation or cost-comparison analysis

4. Retrospective studies

5. Case studies

Following Stage 1 screening, Stage 2 screening was applied as outlined here. Remaining economic evaluation articles were reviewed by two raters and screened independently to verify inclusion/exclusion and for classification as: 1) pertinent, 2) not pertinent, or 3) uncertain pertinence. Full-text articles were reviewed for citations classified as pertinent or uncertain pertinence. Disagreement regarding citations of uncertain pertinence were resolved by discussion with a third rater. Review of full-text articles and associated discussion led to group consensus and ultimate inclusion/exclusion. The following inclusion criteria were applied to studies (12):

1. Included a clinical intervention comparison for patients with TTA

2. Included any one of the following types of economic evaluation:

a. Cost-consequence analysis (CCA), involving a way of reporting cost and an array of outcomes in a separate and disaggregated way so that no incremental ratios are involved

b. $\quad$ Cost-effectiveness analysis (CEA), involving incremental analysis between the calculated differences in costs and outcomes

c. Cost-benefit analysis (CBA), which values both measured health and non-health outcomes in monetary units 
d. $\quad$ Cost-utility analysis (CUA), involving utilities, qualityadjusted life years (QALY), or their variants as the measured outcomes

e. Cost-identification analysis (CIA), in which a cost comparison is made without the inclusion of a comparison of health outcomes

3. Published within the aforementioned timeline

\section{Data Extraction}

Data were extracted and categorized according to country origin, economic evaluation analysis design (trial- or modeling-design), economic evaluation type (CCA, CEA, CBA, CUA, or CIA as defined above), perspective, time horizon, intervention and follow-up period, study population, alternatives compared, costs, and outcomes. Reported costs were converted to U.S. dollars by dividing the local currency unit with the purchasing power parity rates for the mentioned price year and subsequently inflated to 2016 year dollars as defined by the World Bank Group $(13,14)$. If the price-year was not stated in the study, the publication year was used. Final costs displayed were rounded to the nearest whole number. If possible, data were evaluated as appropriate for pooled analyses.

\section{Sorting by Topic}

Following screening for eligibility determination and data extraction, articles were sorted for pertinence into available intervention topical areas.

\section{Quality Assessment}

Economic Evaluation Quality-Each manuscript was assessed for its economic evaluation quality by two reviewers using the Quality of Health Economic Studies (QHES) instrument and the per-item scores averaged (15). In its original form, QHES has 16 weighted criteria scored (scaled 1 to 100). Full weight is awarded for a 'yes' and no weight for a 'no' response per criterion. Weights are relative to the per-criterion importance. This better discriminates between poor and good quality economic evaluations and is suitable for both trial- and modeling-based evaluation (16). QHES has good reliability (17) and construct validity $(18)$ and is a commonly used tool $(16,17,19)$. Its major limitation is its multi-topic items in a single criterion (i.e., multiple items within a single item share a single weight). For this review, the QHES scoring system was modified without changing the original weights to overcome this drawback in accordance with previous use (12). Multi-topic questions were assigned sub-weights per item but still summed to the original weight. Items 12 and 13 were modified to rate both trial- and modeling-based economic evaluation. Item 6 was modified to enable the ability to rate CBA evaluations; however, it was still not applicable to CCA. Thus, the total base score was 94 for CCA evaluations. The score of item 4 did not count when it was not applicable, but the total score remained 100 since its weight was small and only negligibly affected the overall score.

After determining the total scores and converting to a percentage, a total QHES score of 75 to 100 indicated "high quality," 50 to 74 indicated "fair quality," 25 to 49 indicated "poor 
quality," and 0 to 24 indicated "extremely poor quality" (12). Following the rating for economic evaluation with QHES, methodological quality of included studies was rated as described below.

Evaluation of Internal and External Validity-Methodological quality of included publications was independently assessed by two reviewers according to the American Academy of Orthotists and Prosthetists (AAOP) State-of-the-Science Evidence Report Guidelines protocol (20). The AAOP Study Design Classification Scale was used to describe the design type of the included studies (20). The State of the Science Conference (SSC) Quality Assessment Form was used to rate the methodological quality of studies classified as experimental (E1 to E5) or observational (O1 to O6) (20). The form identifies 18 potential threats to internal validity, with the first four threats not applicable for study classifications E3 to E5 and the first five threats not applicable for classifications O1 to O6. Threats were evaluated and tabulated. The internal and external validity of each study was then subjectively rated as "high," "moderate," or "low" based on the quantity and importance of threats present. For internal validity, 0 to 3 threats was rated "high," 4 to 6 threats as "moderate," and 7 to 13 or 14 threats as "low." For external validity, the form identifies eight threats. For this study, 0 to 2 threats to external validity was rated "high," 3 to 5 threats as "moderate," and 6 to 8 threats as "low." Each study was then given an overall quality of evidence of "high," "moderate," and "low" outlined by the AAOP State-of-the-Science Evidence Report Guidelines (20).

The overall ratings from the QHES and from the AAOP State-of-the-Science Evidence Report Guidelines were used in assigning confidence to the developed empirical evidence statements described in following section.

Empirical Evidence Statements-Based on results from the included publications, empirical evidence statements (EES) were developed that compared TTA interventions economically. Reviewers rated the level of confidence of each EES as "high," "moderate," "low," or "insufficient" based on the number of publications contributing to the statement, the methodological quality of those studies, and whether the contributing findings were confirmatory or conflicting as similarly outlined by others (21).

\section{RESULTS}

\section{Literature Search}

The search yielded 292 manuscripts (Figure 1). Stage 1 screening eliminated 263 manuscripts and stage 2 screening an additional 23 manuscripts, leaving six articles meeting eligibility criteria. The six remaining articles, published from 2004 to 2011, were divided into the following three topical areas:

1. $\quad$ Care Models $(n=1)(22)$

2. Prosthetic Treatment $(n=2)(23,24)$

3. Prosthetic Sockets $(n=3)(25-27)$ 
Three of the articles were published in Prosthetics and Orthotics International. The remaining three papers were published in other journals. From an economic evaluation type, all six papers were trial-design (as opposed to modeling). Five were cost-consequence evaluations and one was a cost-identification design (Table 1).

\section{Funding}

Four of the six manuscripts included a statement disclosing whether or not the study was funded. Of these, only two of the studies were funded, one by multiple sources (professional association, governmental, educational) (23) and the other by an insurer (26).

\section{Study Demographics, Interventions, and Outcome Measures}

Articles in this review included a total of 704 patients. Among them, 460 were undergoing limb salvage, whereas the remaining 244 had TTA of mixed etiology. The median (range) sample size was $n=43$ (20 to 484). See Table 1 for extracted study data, including specific characteristics of the subjects and studies. The reviewed studies were classified into three of the 15 potential study designs (controlled trial, randomized controlled trial, and case-control designs) described by the AAOP Study Design Classification Scale (20). All three of the socket manuscripts represented experimental study designs, while the remaining three utilized observational designs. Clinical outcome measures reported in the reviewed publications included duration of care, perceived function, prosthetic satisfaction, clinical gait outcomes, time to prosthetic delivery, and number of visits. Economic outcomes reported in the reviewed publications included cost of prosthetic fabrication, prosthetic maintenance, prosthetic provision, amputation or limb reconstruction surgical costs, and total care costs.

\section{Economic Study Quality}

All six studies were trial designs, so there were no modeling designs. All included studies represented the perspective of the provider, facility, and system with only the exception of the Datta et al. (25) study, which included elements from the patient perspective (e.g., travel considerations). Time horizon was reported in the Care Model (two years) and Prosthetic Treatment papers (40 months to two years). No time horizon was reported in the Prosthetic Socket papers. Conversely, follow-up periods were reported or discernable in every case. Criteria 5 (statistical and sensitivity analyses) and 6 (incremental cost comparison) were the least included criteria of the involved studies. Normann et al. (27) was the only study that included methods to address uncertainty, which was not addressed in any of the other studies. The conduct of incremental analyses between alternative interventions was not done in any of the included studies (i.e., all were cost-identification or cost-consequence trial designs). Generally, positive attributes of the studies included clear and measurable presentation of objectives, use of detailed methodology for data extraction, and appropriate utilization of primary outcome measures. Other positive attributes of the included studies included the use of reliable and well justified measures, the measurement of appropriate costs, the inclusion of descriptions of assumptions and study limitations, and conclusions that were generally based on study results. Overall, five of the studies were rated as fair quality. The remaining paper, Mackenzie et al. (23), was rated as high quality according to the QHES (Table 2). 


\section{Internal and External Validity}

Threats to internal validity included lack of blinding, not addressing fatigue and learning, and not reporting effect size. Areas needing improvement for internal validity were issues with attrition and statistical analyses. Use of robust outcome measures was among the stronger criteria bolstering internal validity. Two studies had low, three had moderate level, and one study had high internal validity. Conversely, all of the studies had high external validity according to the AAOP rating tool. Bias risk from a research funding perspective was low given the majority of studies were unfunded.

\section{Economic Data}

Key cost comparisons and outcomes are extracted into Table 1. Regarding Care Models, the average labor cost per patient was $27 \%$ less costly in the public sector and was coupled with an improvement $(p<0.001)$ in patient satisfaction relative to the private sector care model.

For Prosthetic Treatment, when limb salvage was the comparator, two different studies yielded mixed results. Mackenzie et al. reported no practical difference in length of hospital stay between all average limb salvage scenarios (17.9 days) and TTA (17.4 days). However, their analysis concluded that two-year costs were $6 \%$ higher $(\$ 4,928)$ for TTA versus limb salvage. Importantly, the nature of the limb trauma and type of limb salvage procedure are factors, and, in some limb salvage situations, two-year costs may be as much as $5 \%$ higher than TTA. In a study of those with Charcot foot and other comorbidities, one-year total care costs (i.e., hospitalization, device) were compared between those undergoing limb salvage versus TTA. In this specific population, the limb salvage surgery and the total cost of care, including hospitalization, device provision, therapy, etc., were reportedly more costly with limb salvage than TTA. The average cost increase for limb salvage was $\$ 7,461$ or a $13 \%$ increase even with the added expense of the prosthesis for the TTA cases.

Three studies supported the Prosthetic Socket topic. Two of the studies compared specific weight-bearing (PTB) sockets with forms of total-contact sockets (hydrostatic design (HSD) and total surface bearing (TSB)). Both studies conclude that provision costs of PTB sockets are $60 \%$ ( $p<0.01)$ of those of total-contact alternatives. The tradeoff for the reduced provision costs associated with PTB sockets are increased provision time (three-fold increase; $p<0.05)$ and more visits $(p<0.05)$ necessary to achieve a proper fit. Clinical outcomes were similar between socket designs and preference was for the newer socket regardless of which design it was. Also within the Prosthetic Socket Topic was a comparison of a direct fabrication technique compared with traditional plaster casting methods. The direct manufacturing method was associated with $32 \%$ higher provision costs $(p<0.01)$ but had the benefit of $58 \%$ faster delivery $(p<0.01)$ and 1.5 fewer visits.

\section{Evidence Statements}

Five EESs (Table 3) were synthesized from the results within the three topical areas previously identified. Four of the statements were supported by a single study resulting in an insufficient level of confidence. One statement from the Prosthetic Socket topical area had two studies with moderate and fair quality, respectively, from their validity and economic 
assessment, resulting in moderate confidence in the statement from both the clinical science and economic perspectives.

\section{DISCUSSION}

One purpose of this scoping review was to formulate evidence statements and determine cost efficacy using economic evaluations of interventions provided to patients with TTA. Three topical areas, Care Models, Prosthetic Treatment, and Prosthetic Sockets, were identified, yielding synthesis of five evidence statements. The first statement addresses public versus private care models at the point in care when an interim prosthesis is utilized by patients (22). Under the public model, a prosthetist was employed to provide prostheses, whereas patients were referred out to external private practice prosthetists for artificial limb provision under the private care model. Briefly, clinical outcomes were determined to be similar between the models, yet patient satisfaction was higher and costs were approximately $29 \%$ lower per patient when care was received from the public sector compared with the private sector care model. In this case, payors received the added value of cost savings in addition to higher patient satisfaction with comparable clinical outcomes. The evidence statement is supported by a single study that has high internal and external validity and fair quality as rated by the QHES (Tables 2 and 3), thus providing high confidence in the clinical outcomes and moderate confidence in the economic analysis. However, despite generally favorable scientific and economic quality ratings from a single study, this is insufficient to support the statement until further studies can confirm the findings. Another consideration for this statement is that the study represents the single country of Australia. While other countries have socialized medical models, various nations' approaches to the provision of socialized health care differ considerably. For comparison, the Veterans Affairs Amputation System of Care (VA ASoC) is a U.S. government (i.e., public) sector health care system charged with providing care for the unique population of military service Veterans with limb loss (28). The VA ASoC's mission differs considerably from socialized models charged with care provision for an entire country's population, and there is no clear private sector alternative to compare outcomes within the U.S. Therefore, further study is needed to determine if results of this study (22) are repeatable in other nations or sectors.

The second topical area was Prosthetic Treatment. This topical area yielded two EESs. Both statements compared limb salvage with TTA. Factors included were surgical costs, device provision, and associated costs. The first statement involved patients who experienced lower limb trauma requiring either limb salvage or TTA. Their hospitalization times were similar regardless of the choice of surgical procedure. However, the average two-year costs were $6 \%$ higher for those undergoing TTA compared to those undergoing limb salvage. This higher cost of TTA with associated care is not always the case. For instance, in some limb salvage situations, the extent of the limb trauma and type of limb salvage procedure can necessitate up to 5\% higher costs compared with TTA (23). This EES is supported by a single study that has low internal and high external validity and high quality as rated by the QHES, thus providing moderate confidence in the clinical outcomes and high confidence in the economic analysis. Nevertheless, the single study supporting this statement has disagreement within it about costs relative to the specific levels of amputation and certain types of limb salvage procedures. Therefore, additional evidence is needed to support this 
EES given that only a single study supports the statement and the fact that costs differ depending upon so many factors. Further, both amputation and limb salvage result in neuromusculoskeletal deficit, which can lead to pain and loss of strength, power generation, range of motion, and sensation. These impairments can impact function and quality of life. Clinical outcomes following amputation have been compared to those following limb salvage (29). A definitive advantage to either has not been identified (30-33). This further confirms the autonomy that practitioners must have when discussing options with patients facing this decision due to an inability to empirically identify clear functional or economic advantages related to either decision given currently available data.

Also within the Prosthetic Treatment topic, EES 3, which addresses patients with Charcot foot arthropathy and multiple comorbidities such as diabetes and obesity, was synthesized. In this study, patients reportedly experienced up to $13 \%$ increased one-year costs (including hospitalization, device provision, and therapy) if limb salvage was selected as opposed to TTA. This is a different clinical situation than that described in EES 2 due to the etiology and comorbidities of the respective patients. The statement is supported by a single study that has low internal and high external validity and fair quality as rated by the QHES. Clinical outcomes were not reported. Therefore, evidence supporting this statement is also insufficient due to a lack of data to confirm support. Unlike the previous scenario, in which trauma drives the decision to surgically salvage or amputate, authors in this study unanimously report increased cost associated with limb salvage in the obese diabetic patient with Charcot arthropathy. This warrants further consideration, as obesity has not been shown to significantly impair ambulation or prognosis with a prosthesis (34).

Prosthetic Sockets represent the third topical area in the review. This topic also resulted in the synthesis of two evidence statements. The first statement in this topic (EES 4) states that provision of specific weight-bearing PTB sockets for patients with TTA cost $40 \%$ less than total-contact socket alternatives. However, PTB sockets require up to three times longer to achieve a proper fit with no clinical performance differences among the alternatives. Therefore, according to the included studies $(25,26)$, there is no cost reduction or clinical performance difference between the interventions. Although the PTB sockets have a lower initial cost, the additional clinic visits, which require increased time commitments and travel costs as well as the risk of potential complications, ultimately increase latent costs.

Conversely, provision of the more costly (initial cost) total-contact alternative sockets results in fewer of these additional expenses and visits. Thus, the interventions appear to be economically equivalent when viewed from all stakeholder perspectives in the short term. This fourth EES is supported by two studies, both with moderate internal validity and high external validity $(25,26)$. Both are rated as fair quality studies according to the QHES. This evidentiary support provides moderate confidence in the clinical outcomes and fair confidence in the economic analysis. In contrast to these studies, a recent systematic review suggests that use of gel-lined sockets, as opposed to traditional PTB sockets, results in numerous clinical benefits, including decreased walk aid dependence, improved suspension options, improved load distribution, decreased pain, and increased comfort (35). This systematic review of clinical studies suggests gel-lined sockets offer clinical improvements relative to PTB sockets and is supported by Level 1 evidence. Thus, if clinical outcomes are improved with total-contact sockets, users may realize greater value through their use 
relative to PTB alternatives. This particular topic and EES also point out the importance of considering all perspectives in an economic analysis. A limitation of this EES is the time horizon. It is unclear if there are potential functional or cost differences over the long term between specific weight-bearing and total-contact socket alternatives.

The second statement (EES 5) within the Prosthetic Socket topic addresses traditional plaster casting fabrication with direct manufacturing methods of providing prosthetic sockets for patients with TTA. Direct fabrication methods of socket delivery reportedly have $32 \%$ higher initial provision costs but are delivered to patients up to $58 \%$ faster and in fewer visits. This EES is supported by a single study with moderate internal validity and high external validity. It is rated as fair quality according to the QHES. This evidentiary support provides moderate confidence in the clinical outcomes and fair confidence in the economic analysis. Again, further studies are needed to strengthen confidence in EES 5. Additionally, authors were unable to locate data to support widespread adoption of direct manufacturing techniques for TTA socket provision.

A second purpose of this scoping review was to determine if further review and analysis is indicated based on the current state of the economic science relative to care for the patient with TTA. It seems that further analysis of economic comparison studies is less of an issue compared with the need for further primary economic comparison research, input, and guidance from the profession relative to a strategy to further develop this area of research. Additionally, multiple manuscripts were excluded from this analysis of economic comparisons that alternatively provide descriptive economic information relative to care for persons with TTA. These excluded narrative economic papers merit further review and analysis and are currently being evaluated by the authors.

\section{Limitations}

Many subjects in this report were patients of limb salvage procedures selected for comparison to TTA cases. Unfortunately, many individual aspects of transtibial prosthetic intervention are not represented or are under-represented in the health care economic literature. Currently, economic evaluations in any area of transtibial patient care are limited. There were no cost-benefit, cost-effectiveness, or cost-utility analyses identified in this search, as all available studies were cost-identification or cost-consequence studies. No economic modeling was identified. Further, described services and interventions were not quantifiably connected directly to health measures. Therefore, more sophisticated and comprehensive economic evaluations are needed with regard to transtibial interventions to better understand the potential value of certain interventions for the patient with TTA. One possible solution is to incorporate outcomes conducive to economic analysis and modeling as part of prosthetic oriented clinical trials (35). While total prosthetic care has some representation, discrete topics of interest to the prosthetic clinical community were not represented, including topics such as prosthetic suspension, feet, newer socket designs (i.e., elevated vacuum), and others. Finally, this body of literature is biased to include predominantly the perspective of the care provider, their practice facility, or a care system. These are limited because cost burden to society, the patient, or the payor are not accounted for. 


\section{CONCLUSIONS}

The comparative economic literature in transtibial prosthetics is presently insufficient for further review, conclusion, and policy guidance. Six cost-identification or cost-consequence articles were eligible for scoring in three topical areas: Care Models, Prosthetic Treatment, and Prosthetic Sockets. From these, five evidence statements were synthesized, with one supported by sufficient evidence to provide moderate confidence regarding comparable cost between total-contact and specific weight-bearing socket designs when clinic visits, adjustments, and initial costs are considered in the short term. Further and more sophisticated economic analyses of transtibial prosthetic interventions are needed in order to determine value related to device provision and maintenance, outcomes, and health. Where further primary comparative economic analyses of TTA prosthetic care are needed, analyses of narrative economic reports relative to TTA care may be sufficient to warrant further review. Finally, guidance from the profession may be useful in devising a strategy for how to assure economic analyses are a routine element of prosthetic science in the future.

\section{Acknowledgments}

Contents of this manuscript represent the opinions of the authors and not necessarily those of the U.S. Department of Defense, U.S. Department of the Army, U.S. Department of Veterans Affairs, or any academic or health care institution. Authors declare no conflicts of interest. This project was funded by the American Orthotics and Prosthetics Association, the American Academy of Orthotists \& Prosthetists, and the National Institutes of Health Scholars in Patient Oriented Research (SPOR) grant (1K30RR22270).

\section{REFERENCES}

1. Blough DK, Hubbard S, McFarland LV, Smith DG, Gambel JM, Reiber GE. Prosthetic cost projections for servicemembers with major limb loss from Vietnam and OIF/OEF. J Rehabil Res Dev. 2010; 47(4):387-402. [PubMed: 20803406]

2. Levinson, DR. Washington (DC): U.S. Dept. of Health and Human Services; 2011. Questionable billing by suppliers of lower limb prostheses.

3. Dillingham TR, Pezzin LE, Shore AD. Reamputation, mortality, and health care costs among persons with dysvascular lower-limb amputations. Arch Phys Med Rehabil. 2005; 86(3):480-486. [PubMed: 15759232]

4. Hofstad CJ, van der Linde H, van Limbeek J, Postema K. Prescription of prosthetic ankle-foot mechanisms after lower limb amputation. Cochrane Database Syst Rev. 2004; (1):CD003978. [PubMed: 14974050]

5. Smith DG, McFarland LV, Sangeorzan BJ, Reiber GE, Czerniecki JM. Postoperative dressing and management strategies for transtibial amputations: a critical review. J Prosthet Orthot. 2004; 16(3S): $15-25$.

6. Amputee Coalition of America. Manassas (VA): Amputee Coalition of America; Prosthetic coverage: saving money and saving lives. http:/www.hangerclinic.com/new-patient/Documents/ prosthetic-coverage-saving-lives.pdf [Accessed 2015 Dec 15]

7. Gailey R, Allen K, Castles J, Kucharik J, Roeder M. Review of secondary physical conditions associated with lower-limb amputation and long-term prosthesis use. J Rehabil Res Dev. 2008; 45(1):15-29. [PubMed: 18566923]

8. Penn-Barwell JG. Outcomes in lower limb amputation following trauma: a systematic review and meta-analysis. Injury. 2011; 42(12):1474-1479. [PubMed: 21831371]

9. Bragaru M, Dekker R, Geertzen JH, Dijkstra PU. Amputees and sports: a systematic review. Sports Med. 2011; 41(9):721-740. [PubMed: 21846162] 
10. Webster JB, Hakimi KN, Williams RM, Turner AP, Norvell DC, Czerniecki JM. Prosthetic fitting, use, and satisfaction following lower-limb amputation: a prospective study. J Rehabil Res Dev. 2012; 49(10):1493-1504. [PubMed: 23516053]

11. Dobson DaVanzo \& Associates, LLC. Vienna (VA): Dobson DaVanzo \& Associates, LLC; 2013. Retrospective cohort study of the economic value of orthotic and prosthetic services among Medicare beneficiaries. Final report. http://mobilitysaves.org/docs/ Dobson_Davanzo_Study_on_Cost_Effectiveness.pdf. 2013 [accessed 2015 Mar 31]

12. Yong YV, Shafie AA. Economic evaluation of enhanced asthma management: a systematic review. Pharm. Pract. (Granada). 2014; 12(4):493. [PubMed: 25580173]

13. World Development Indicators. [accessed 2015 Oct 12] PPP conversion factor (GDP) to market exchange rate ratio. The World Bank Group. 2015. http://data.worldbank.org

14. World Development Indicators. [accessed 2015 Oct 12] Inflation, GDP deflator (annual \%). The World Bank Group. 2015. http://data.worldbank.org

15. Chiou CF, Hay JW, Wallace JF, Bloom BS, Neumann PJ, Sullivan SD, Yu HT, Keeler EB, Henning JM, Ofman JJ. Development and validation of a grading system for the quality of costeffectiveness studies. Med Care. 2003; 41(1):32-44. [PubMed: 12544542]

16. Langer A. A framework for assessing Health Economic Evaluation (HEE) quality appraisal instruments. BMC Health Serv Res. 2012; 12:253. [PubMed: 22894708]

17. Spiegel BM, Targownik LE, Kanwal F, DeRosa V, Dulai GS, Gralnek IM, Chiou CF. The quality of published health economic analyses in digestive diseases: a systematic review and quantitative appraisal. Gastroenterol. 2004; 127(2):403-411.

18. Walker, DG.; Wilson, RF.; Sharma, R.; Bridges, J.; Niessen, L.; Bass, EB.; Frick, K. Rockville (MD): Agency for Healthcare Research and Quality (US); 2012. Best practices for conducting economic evaluations in health care: a systematic review of quality assessment tools.

19. Peterson LE, Goodman C, Karnes EK, Chen CJ, Schwartz JA. Assessment of the quality of cost analysis literature in physical therapy. Phys Ther. 2009; 89(8):733-755. [PubMed: 19556332]

20. Hafner, B. Washington (DC): American Academy of Orthotists \& Prosthetists; 2008. State of the science evidence report guidelines.

21. Carey SL, Lura DJ, Highsmith MJ. Differences in myoelectric and body-powered upper-limb prostheses: systematic literature review. J Rehabil Res Dev. 2015; 52(3):247-262. [PubMed: 26230500]

22. Gordon R, Magee C, Frazer A, Evans C, McCosker K. An interim prosthesis program for lower limb amputees: comparison of public and private models of service. Prosthet Orthot Int. 2010; 34(2):175-183. [PubMed: 20184499]

23. MacKenzie EJ, Jones AS, Bosse MJ, Castillo RC, Pollak AN, Webb LX, Swiontkowski MF, Kellam JF, Smith DG, Sanders RW, Jones AL, Starr AJ, McAndrew MP, Patterson BM, Burgess AR. Health-care costs associated with amputation or reconstruction of a limb-threatening injury. J Bone Joint Surg Am. 2007; 89A(8):1685-1692.

24. Gil J, Schiff AP, Pinzur MS. Cost comparison: limb salvage versus amputation in diabetic patients with charcot foot. Foot Ankle Int. 2013; 34(8):1097-1099. [PubMed: 23493775]

25. Datta D, Harris I, Heller B, Howitt J, Martin R. Gait, cost and time implications for changing from PTB to ICEX (R) sockets. Prosthet Orthot Int. 2004; 28(2):115-120. [PubMed: 15382805]

26. Selles RW, Janssens PJ, Jongenengel CD, Bussmann JB. A randomized controlled trial comparing functional outcome and cost efficiency of a total surface-bearing socket versus a conventional patellar tendon-bearing socket in transtibial amputees. Arch Phys Med Rehabil. 2005; 86(1):154161. quiz 180. [PubMed: 15641007]

27. Normann E, Olsson A, Brodtkorb TH. Modular socket system versus traditionally laminated socket: a cost analysis. Prosthet Orthot Int. 2011; 35(1):76-80. [PubMed: 21515892]

28. Webster JB, Poorman CE, Cifu DX. Guest editorial: Department of Veterans Affairs amputations system of care: 5 years of accomplishments and outcomes. J Rehabil Res Dev. 2014; 51(4):vii-xvi.

29. MacKenzie EJ, Bosse MJ, Pollak AN, Webb LX, Swiontkowski MF, Kellam JF, Smith DG, Sanders RW, Jones AL, Starr AJ, McAndrew MP, Patterson BM, Burgess AR, Castillo RC. Longterm persistence of disability following severe lower-limb trauma. Results of a seven-year followup. J Bone Joint Surg Am. 2005; 87(8):1801-1809. [PubMed: 16085622] 
30. Bosse MJ, MacKenzie EJ, Kellam JF, Burgess AR, Webb LX, Swiontkowski MF, Sanders RW, Jones AL, McAndrew MP, Patterson BM, McCarthy ML, Travison TG, Castillo RC. An analysis of outcomes of reconstruction or amputation after leg-threatening injuries. N Engl J Med. 2002; 347(24):1924-1931. [PubMed: 12477942]

31. Andersen RC, Swiontkowski MF. Moderators' summary: perceived performance differences limb salvage versus amputation in the lower extremity (session II). J Am Acad Orthop Surg. 2011; 19(Suppl 1):S20-S22. [PubMed: 21304042]

32. Doukas WC, Hayda RA, Frisch HM, Andersen RC, Mazurek MT, Ficke JR, Keeling JJ, Pasquina PF, Wain HJ, Carlini AR, MacKenzie EJ. The Military Extremity Trauma Amputation/Limb Salvage (METALS) study: outcomes of amputation versus limb salvage following major lowerextremity trauma. J Bone Joint Surg Am. 2013; 95(2):138-145. [PubMed: 23324961]

33. Busse JW, Jacobs CL, Swiontkowski MF, Bosse MJ, Bhandari M. Evidence-Based Orthopaedic Trauma Working G. Complex limb salvage or early amputation for severe lower-limb injury: a meta-analysis of observational studies. J Orthop Trauma. 2007; 21(1):70-76. [PubMed: 17211275]

34. Kalbaugh CA, Taylor SM, Kalbaugh BA, Halliday M, Daniel G, Cass AL, Blackhurst DW, Cull DL, Langan EM 3rd, Carsten CG, York JW, Snyder BA, Youkey JR. Does obesity predict functional outcome in the dysvascular amputee? Am Surg. 2006; 72(8):707-712. discussion 712-703. [PubMed: 16913314]

35. Highsmith MJ, Kahle JT, Miro RM, Orendurff MS, Lewandowski AL, Orriola JJ, Sutton B, Ertl JP. Prosthetic Interventions for people with transtibial amputation: systematic review and metaanalysis of high-quality prospective literature and systematic reviews. J Rehabil Res Dev. 2016; 53(2):157-184. [PubMed: 27149143] 
Articles identified through database searching:

PubMed, CINAHL, Google Scholar

$$
(n=292)
$$

Articles potentially avaialble

for classification of pertinence

Articles Eliminated

Stage 1 Screening

$$
(n=263)
$$

Care Models

$(n=1)$

$$
(n=29)
$$

Figure 1.

Flow diagram. 


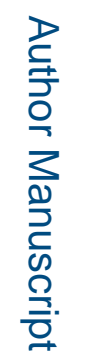

\begin{tabular}{|c|c|c|c|c|c|c|}
\hline 递 & 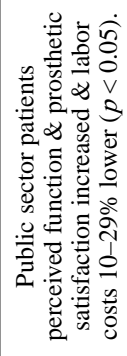 & 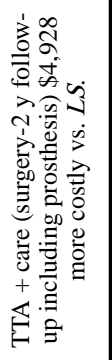 & 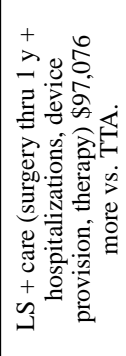 & 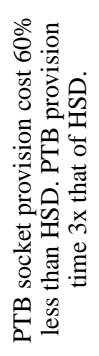 & 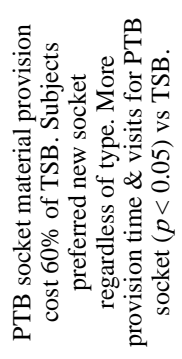 & 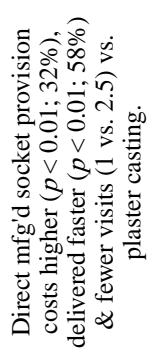 \\
\hline 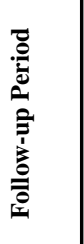 & 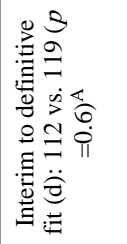 & 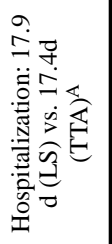 & $\stackrel{\infty}{\beth}$ & $\begin{array}{l}\frac{0}{3} \\
\frac{3}{6}\end{array}$ & 惫 & 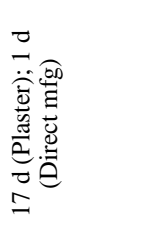 \\
\hline 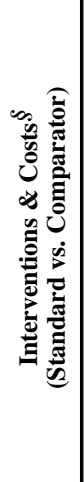 & 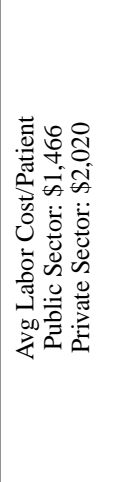 & 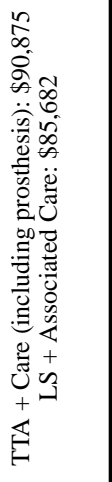 & 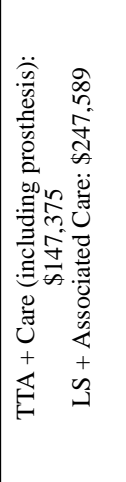 & 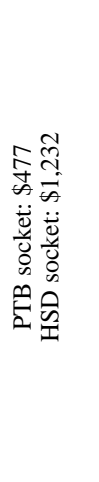 & 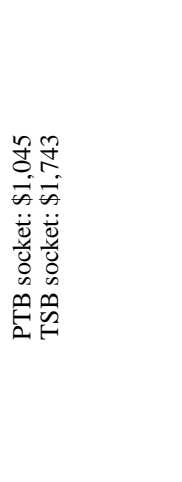 & 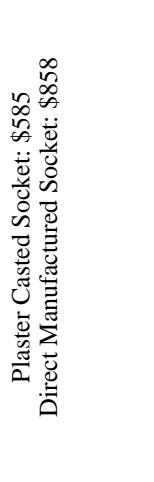 \\
\hline to & 8 & $\stackrel{1}{\stackrel{*}{*}} \stackrel{\vec{y}}{q}$ & 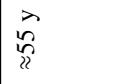 & $\overrightarrow{\hat{n}}$ & 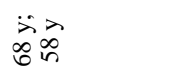 & बें \\
\hline 突 & 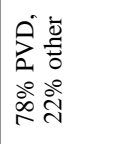 & 䔍 & 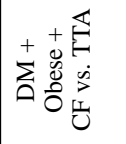 & 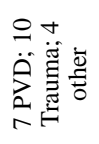 & 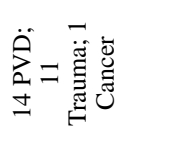 & 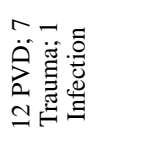 \\
\hline$=$ & 8 & 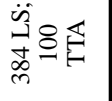 & 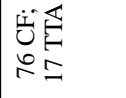 & $\bar{\lambda}$ & $\underset{v}{ }$ & নి \\
\hline 莙 & 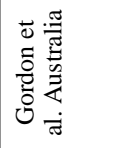 & 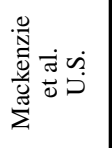 & 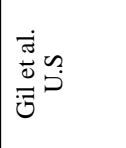 & 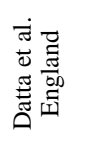 & 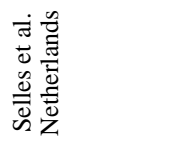 & 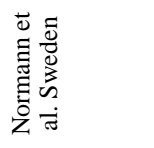 \\
\hline 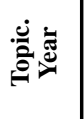 & 总离离高 & 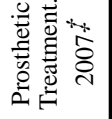 & 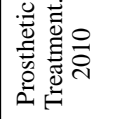 & 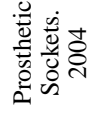 & 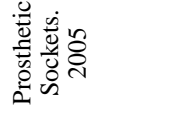 & 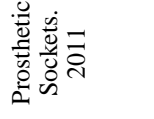 \\
\hline
\end{tabular}




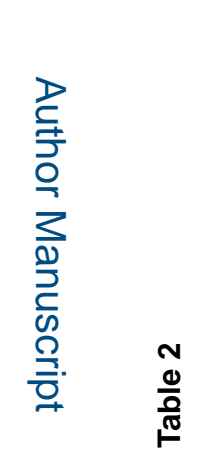

\begin{tabular}{|c|c|c|c|c|c|c|c|}
\hline 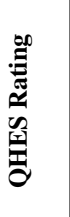 & 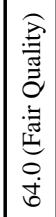 & 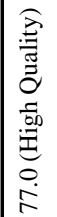 & 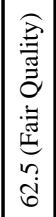 & 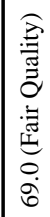 & 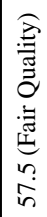 & 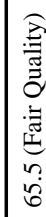 & \\
\hline 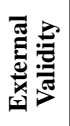 & 总 & 点 & 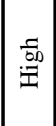 & $\mid \begin{array}{l}\frac{-}{50} \\
:\end{array}$ & 点 & $\frac{r}{60}$ & \\
\hline 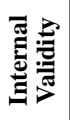 & 总 & 童 & $\mid \begin{array}{l}3 \\
0 \\
0\end{array}$ & $\stackrel{\nabla}{\Sigma}^{\circ}$ & $\frac{\sigma}{\Delta}$ & $\stackrel{\overrightarrow{0}}{\Sigma}$ & \\
\hline 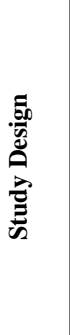 & 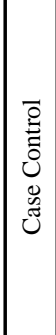 & 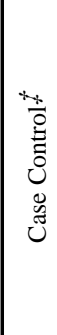 & 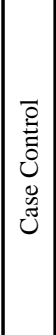 & 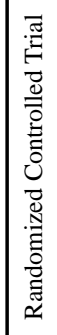 & 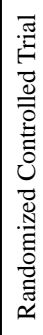 & 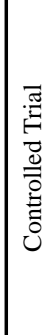 & \\
\hline 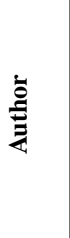 & 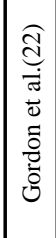 & 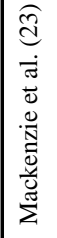 & 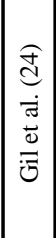 & 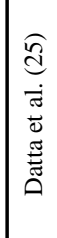 & 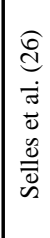 & 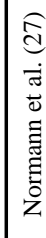 & \\
\hline 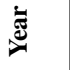 & $\stackrel{\circ}{\grave{i}}$ & 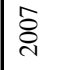 & $\stackrel{\circ}{\stackrel{2}{*}}$ & 壳 & 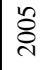 & $\bar{\Xi}$ & \\
\hline 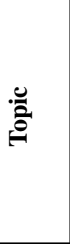 & $\begin{array}{l}n \\
\frac{a}{0} \\
\frac{0}{0} \\
\sum_{0} \\
0 \\
\tilde{j}\end{array}$ & 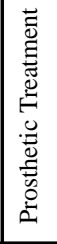 & 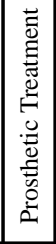 & 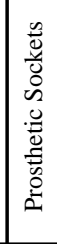 & 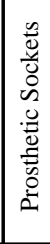 & 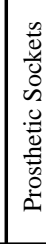 & \\
\hline
\end{tabular}

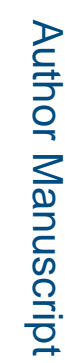

롤 
Table 3

Empirical Evidence Statements

\begin{tabular}{|c|c|c|}
\hline Category & Empirical Evidence Statement (EES) & $\begin{array}{l}\text { Supporting } \\
\text { Studies }\end{array}$ \\
\hline Care Models & $\begin{array}{l}\text { (EES 1) In socialized healthcare systems, patients } \\
\text { with unilateral transtibial amputation may experience } \\
\text { similar clinical outcomes from the interim to definitive } \\
\text { prosthetic stages of rehabilitation with lower average } \\
\text { per-patient labor costs and higher satisfaction when } \\
\text { managed in a public sector care model compared with } \\
\text { a private sector care model. }\end{array}$ & High/Fair(22) \\
\hline $\begin{array}{l}\text { Prosthetic } \\
\text { Treatment }\end{array}$ & $\begin{array}{l}\text { (EES 2) Patients having experienced lower limb } \\
\text { trauma requiring limb salvage or transtibial } \\
\text { amputation will likely experience similar } \\
\text { hospitalization duration regardless of the choice of } \\
\text { surgical procedure. However, the two-year costs, on } \\
\text { average, will be approximately } 6 \% \text { higher for TTA } \\
\text { versus limb salvage. In some situations, the limb } \\
\text { trauma and type of limb salvage procedure can } \\
\text { necessitate up to 5\% higher costs compared with } \\
\text { TTA. }\end{array}$ & $\begin{array}{l}\text { Moderate/High } \\
\text { (23) }\end{array}$ \\
\hline $\begin{array}{l}\text { Prosthetic } \\
\text { Treatment }\end{array}$ & $\begin{array}{l}\text { (EES 3) Patients with Charcot foot arthropathy and } \\
\text { multiple comorbidities will likely experience up to 13\% } \\
\text { increased one-year costs (including hospitalization, } \\
\text { device provision, therapy) if limb salvage is selected } \\
\text { as opposed to transtibial amputation. }\end{array}$ & $\begin{array}{c}\text { Moderate/Fair } \\
\text { (24) }\end{array}$ \\
\hline $\begin{array}{l}\text { Prosthetic } \\
\text { Sockets }\end{array}$ & $\begin{array}{l}\text { (EES 4) Provision of patella tendon bearing (PTB) } \\
\text { sockets for patients with transtibial amputation costs } \\
40 \% \text { less than total contact socket alternatives } \\
\text { however PTB sockets require up to three-times longer } \\
\text { to achieve a proper fit with no clinical performance } \\
\text { differences between the alternatives. }\end{array}$ & $\begin{array}{c}\text { Moderate/Fair } \\
\text { Two studies } \\
(25,26)\end{array}$ \\
\hline $\begin{array}{l}\text { Prosthetic } \\
\text { Sockets }\end{array}$ & $\begin{array}{l}\text { (EES 5) Compared with traditional plaster casting } \\
\text { fabrication, the direct manufacturing method of } \\
\text { providing prosthetic sockets for patients with } \\
\text { transtibial amputation have } 32 \% \text { higher provision } \\
\text { costs but are delivered to patients up to } 58 \% \text { faster } \\
\text { and in fewer visits. }\end{array}$ & $\begin{array}{c}\text { Moderate/Fair } \\
\text { (27) }\end{array}$ \\
\hline
\end{tabular}

Supporting Studies rated by AAOP tool/QHES. The Level of Confidence for EESs 1-3 and 5 is Insufficient based on limited evidence (i.e. a single study per topic). The fourth statement (EES 4) is supported by sufficient evidence to support a Moderate level of confidence in the statement. 